\title{
Pulmonary and systemic hepatocyte and keratinocyte growth factors in patients with chronic obstructive pulmonary disease
}

\author{
Jaume Sauleda' \\ Aina Noguera ${ }^{2}$ \\ David Blanquer ${ }^{3}$ \\ Jaume Pons ${ }^{4}$ \\ Meritxell López' \\ Cristina Villena' \\ Alvar GN Agustíl \\ 'Servei de Pneumologia, Hospital \\ Universitari Son Dureta, Fundació \\ Caubet-Cimera Illes Balears, Illes Balears, \\ CIBER Enfermedades respiratorias, Illes \\ Balears, Spain; ${ }^{2}$ Inmunologia; ${ }^{4}$ Anàlisis \\ Clínique, Hospital Universitari Son \\ Dureta, Palma Mallorca, Spain; ${ }^{3}$ Fundació \\ Hospital Manacor, Manacor, Illes \\ Balears Spain
}

Background: The potential role of growth factors in chronic obstructive pulmonary disease (COPD) has begun to be addressed only recently and is still poorly understood. For this study, we investigated potential abnormalities of hepatocyte growth factor (HGF) and keratinocyte growth factor (KGF) in patients with COPD.

Methods: To this end, we compared the levels of HGF and KGF, measured by enzyme-linked immunosorbent assay (ELISA), in bronchoalveolar lavage (BAL) fluid and in serum in 18 patients with COPD (62 $\pm 9 \mathrm{yrs}$, forced expiratory volume in one second $\left[\mathrm{FEV}_{1}\right] 57 \pm 12 \%$ ref, $\mathrm{X} \pm$ standard deviation of mean), 18 smokers with normal lung function ( $58 \pm 8 \mathrm{yrs}, \mathrm{FEV}_{1} 90 \pm 6 \% \mathrm{ref}$ ) and 8 never smokers ( $67 \pm 9$ yrs, $94 \pm 14 \%$ ref).

Results: We found that in BAL, HGF levels were higher in patients with COPD than in the other two groups whereas, in serum, HGF concentration was highest in smokers with normal lung function $(\mathrm{p}<0.01)$. KGF levels were not significantly different between groups, neither in blood nor in BAL (most values were below the detection limit).

Conclusions: These results highlight a different response of HGF in BAL and serum in smokers with and without COPD that may be relevant for tissue repair in COPD.

Keywords: COPD, growth factors, tissue repair

\section{Introduction}

Chronic obstructive pulmonary disease (COPD) is characterized by extensive lung damage, which is believed to result from the abnormal inflammatory response that occurs in the so-called susceptible smokers in response to inhaled particles and gases, mostly, tobacco smoking (Rabe et al 2007). The potential role of repair processes in COPD has begun to be addressed only recently and is still poorly understood.

Growth factors are key controllers of repair. In the lungs, hepatocyte growth factor (HGF) and keratinocyte growth factor (KGF), also known as fibroblast growth factor-7, are particularly relevant due to their capacity to stimulate alveolar and bronchial epithelial cell proliferation (Mason 2002; Bonay et al 2005). HGF is a multifunctional heterodimeric protein with mitogenic properties that is synthesized by a variety of lung cell types, including fibroblasts, macrophages, smooth muscle cells and epithelial cells (Mason 2002). In humans, HGF expression increases in serum after pneumonectomy (Sugahara et al 1998) and acute lung injury (ALI) (Stern et al 2000). In experimental animals in vivo gene transfection of HGF ameliorates pulmonary emphysema (Shigemura et al 2005) and drug-induced pulmonary injury (Dohi et al 2000). On the other hand, KGF is a heparin-binding mitogen secreted primarily by fibroblasts (Ulich et al 1994) and T lymphocytes (Boismenu et al 1994). Like HGF, KGF increases after lung injury in humans (Stern et al 2000) and minimizes lung injury in experimental animals (Welsh et al 2000). 
The role of HGF and KGF in COPD has been addressed by two previous studies. Plantier and colleagues (2005) found that cultured fibroblasts harvested from patients with emphysema produced less HGF (but similar amounts of KGF) than controls, and Bonay and colleagues (2005) found a direct relationship between the severity of airflow obstruction and HGF mRNA content in lung samples of smokers. These two studies suggest, therefore, that the pulmonary regulation of HGF may be abnormal in patients with COPD. However, both HGF and KGF can also be released by extrapulmonary organs, thus having the potential to act systemically (Verghese et al 1998; Sekine et al 2004). Given the current clinical relevance attributed to the systemic effects of COPD (Agusti et al 2003), in this study we compared the levels of HGF and KGF in the pulmonary (bronchoalveolar lavage [BAL] fluid) and systemic compartment (circulating blood) of smokers with and without COPD and never smokers.

\section{Methods}

\section{Subjects and ethics}

We studied 18 patients with COPD (GOLD II-III) (Rabe et al 2007), 18 smokers without chronic bronchitis or dyspnea and with normal lung function, and 8 never smokers. All of them required bronchoscopy for clinical purposes mainly to evaluate a solitary pulmonary nodule or a hemoptysis episode in the group of patients with COPD and smokers with normal lung function. The percentage of lung neoplasms was similar in both groups. In the never smoker group, the main indication was hemoptysis or chronic cough. All patients with COPD had not had any exacerbation for at least the three months that preceded their inclusion in the study. All of them were treated with inhaled bronchodilators (salmeterol, salbutamol, ipratropium bromide, and/or tiotropium); 4 patients also received inhaled corticosteroids (ICS), but none received oral steroids. We excluded patients with other chronic lung diseases (asthma, bronchiectasis, and interstitial lung diseases) and cardiac, hepatic, or renal failure. All participants signed an informed consent. The Ethics Committee of our institution approved the study protocol.

\section{Lung function}

A forced spirometry (GS, Warren E. Collins, Braintree, MA, USA) was obtained in all participants (ATS 1995). Spirometric reference values were those of a Mediterranean population (Roca et al 1986).

\section{Blood analysis}

A peripheral venous blood sample $(10 \mathrm{cc})$ was obtained before bronchoscopy by venipuncture from an ante-cubital vein. Samples were immediately centrifuged at $1200 \mathrm{~g}$ during 10 minutes. Thereafter, serum samples were frozen in aliquots at $-80{ }^{\circ} \mathrm{C}$ until analysis. All serum samples were processed identically and analyzed simultaneously at the completion of the study.

\section{Bronchoscopy}

Bronchoscopy was performed with a flexible fiberoptic bronchoscope (Pentax 15v, Tokyo, Japan). Active smokers were requested to refrain from smoking for at least 12 hours before bronchoscopy. This was checked by the exhaled carbon monoxide ( $\mathrm{CO}$ ) concentration (ToxCO, Bedfont, UK), which was lower than $10 \mathrm{ppm}$ in all participants. BAL was performed following the standard methodology (Pons et al 2005). In brief, we instilled eight $25 \mathrm{~mL}$ aliquots $(\mathrm{n}=8)$ of sterile saline solution in one pulmonary segment of one of the middle lobe or lingula not containing any visible lung nodule or infiltrate. Aliquots were placed in plastic recipients and immediately centrifuged at $200 \times \mathrm{g}$ for $10 \mathrm{~min}\left(\right.$ at $4{ }^{\circ} \mathrm{C}$ ), and the supernatant was stored at $-80{ }^{\circ} \mathrm{C}$ until analysis.

We excluded the presence of airway bacterial infection by using a protected specimen brush (PSB) (Mill-Rose Lab, Mentor OH, USA) to sample bronchial secretions before BAL (Wimberley et al 1982). The culture of PBS samples yielded less than $10^{3} \mathrm{CFU} / \mathrm{mL}$ in all participants.

\section{Measurement of HGF and KGF}

The concentration of HGF and KGF in BAL supernatant and serum was measured using a commercially available sandwich enzyme-linked immunosorbent assay (ELISA) kits (Amersham Pharmacia Biotech UK Ltd, Bucks, UK) following the manufacturer's directions (Amersham Pharmacia Biotech UK Ltd). The detection limits of HGF and $\mathrm{KGF}$ were $40 \mathrm{pg} / \mathrm{ml}$ and $15 \mathrm{pg} / \mathrm{ml}$ respectively. HGF and KGF concentrations were corrected for the albumin concentration in BAL like in previous studies (Sakai et al 1997).

\section{Statistical analysis}

Demographic are expressed as mean \pm standard deviation (SD) and biological data as median and range values. One way analysis of variance (ANOVA), followed by post-hoc contrast (Scheffe test) if appropriate, was used to assess the statistical significance of the differences between groups. Correlations between variables of interest were explored using the Spearman test. A p value lower than 0.05 was considered significant. 


\section{Results}

\section{Anthropometric and functional data}

Table 1 presents the main clinical and lung function data of all participants. Age was similar in the three groups. Smoking exposure was higher in patients with COPD (Table 1).

On average patients with COPD showed moderate airflow obstruction whereas, by definition, spirometry was normal in smokers with normal lung function and never smokers.

\section{BAL cell count}

Total cell count was higher in smokers with normal lung function $2 \times 10^{5} / \mathrm{mL}[0.4-7]$ than in nonsmokers $\left(0.5 \times 10^{5} / \mathrm{mL}\right.$ [0.4-1], p $<0.05)$. Patients with COPD also showed a trend towards higher values $\left(1.1 \times 10^{5} / \mathrm{mL}\right.$ [0.5-3.3]) but differences failed to reach statistical significance. Differential cell counts were similar among groups (Table 2).

\section{HGF and KGF concentrations}

The concentration of HGF (corrected for albumin, HGF/ albumin) in BAL was significantly higher in patients with COPD (62 pg/mg of albumin [13-184], $\mathrm{p}<0.01)$ than in smokers with normal lung function $(6.3 \mathrm{pg} / \mathrm{mg}$ of albumin [1-14]) and never smokers (14 pg/mg of albumin [4-25]) (Figure 1). There were no significant differences in albumin concentration in BAL in all groups: COPD, $21 \mathrm{mg} / \mathrm{ml}$ (7.6-44.3); Smokers $19 \mathrm{mg} / \mathrm{ml}$ (9-38 mg/ml); and, never smokers $11 \mathrm{mg} / \mathrm{ml}$ (7-16). In contrast, the serum concentration of HGF was higher $(p<0.01)$ in smokers with normal lung function (1897 $\mathrm{pg} / \mathrm{ml}$ [433-2692]) than in patients with COPD (1053 pg/ml [629-1630]) and never smokers (700 pg/ml [424-986]) (Figure 2).

The concentration of KGF in BAL was undetectable in most individuals. Likewise, 9 patients with COPD and 9 smokers with normal lung function showed undetectable levels of KGF in their serum. In the remaining participants, KGF levels were $70 \mathrm{pg} / \mathrm{ml}$ (27-553) (COPD) and $463 \mathrm{pg} / \mathrm{ml}$ (32-621) (smokers) $(p=0.09)$. All nonsmokers showed undetectable values.

\section{Effect of inhaled corticosteroids}

Only four patients with COPD were receiving therapy with ICS, and results did not change after removing them from the analysis.

\section{Effect of smoking}

As mentioned in methods, all current smokers (irrespective of the presence or absence of airflow obstruction) refrained from smoking for at least 12 hours before bronchoscopy. In patients with COPD we compared the levels of HGF and KGF in current smokers $(n=6)$ and exsmokers $(n=12)$, but we were unable to find any significant difference in HGF levels (BAL, 62 pg/mg albumin [13-156] vs. $58 \mathrm{pg} / \mathrm{mg}$ albumin (15-184); serum, $1057 \mathrm{pg} / \mathrm{ml}$ (629-1406) vs 1057 $\mathrm{pg} / \mathrm{ml}$ (703-1629), respectively). Due to the small number of patients with detectable levels of KGF, we could not compare KGF values in these two subgroups of subjects.

\section{Physiological correlates}

We explored potential relationships between HGF and KGF levels and several variables of interest, such as age, body mass index, severity of airflow obstruction and total and differential cell counts of the BAL but were not able to find any significant relationship. There were no significant relationships between BAL and plasma HGF or KGF concentrations. Likewise, because patients with COPD had a higher smoking exposure we investigated the potential correlation between the latter (pack-yrs) and growth factor concentrations but were unable to find them.

\section{Discussion}

This study compares the pulmonary and systemic concentrations of two key lung growth factors (HGF and KGF) in patients with COPD, smokers with normal lung function and never smokers. We found that HGF levels were significantly increased in BAL in patients with COPD, and in serum in smokers with normal lung function (Figures 1 and 2). In contrast

Table I Clinical and lung function data (mean \pm SD) of all participants

\begin{tabular}{llll}
\hline & Nonsmokers $(\mathbf{n}=\mathbf{8})$ & $\begin{array}{l}\text { Smokers with normal } \\
\text { lung function }(\mathbf{n}=18)\end{array}$ & COPD (n= I8) \\
\hline Age (yr.) & $67 \pm 9$ & $58 \pm 8$ & $62 \pm 7$ \\
Pack-yr. & 0 & $37 \pm 14^{\mathrm{a}}$ & $48 \pm 15^{\mathrm{ab}}$ \\
FEV (\% predicted) & $94 \pm 14$ & $90 \pm 6$ & $57 \pm 12^{\mathrm{ab}}$ \\
FEV /FVC (\%) & $80 \pm 6$ & $76 \pm 5$ & $54 \pm 8^{\mathrm{ab}}$ \\
\hline
\end{tabular}

Notes: ${ }^{\mathrm{a}} \mathrm{p}<0.01$ (vs nonsmokers); ${ }^{\mathrm{b}} \mathrm{p}<0.05$ (vs smokers with normal lung function).

Abbreviations: COPD, chronic obstructive pulmonary disease; $\mathrm{FEV}_{1}$, forced expiratory volume in one second; $\mathrm{FVC}$, forced vital capacity; SD, standard deviation. 
Table 2 Bronchoalveolar lavage fluid total and differential cell counts (Median and range)

\begin{tabular}{llll}
\hline & Nonsmokers $(\mathbf{n}=\mathbf{8})$ & $\begin{array}{l}\text { Smokers with normal lung } \\
\text { function }(\mathbf{n}=\mathbf{1 8})\end{array}$ & COPD (n= I8) \\
\hline Total cell count $\left(\times 10^{5} / \mathrm{mL}\right)$ & $0.5(0.4-1)$ & $2(0.4-7)^{*}$ & $1.1(0.5-3.3)$ \\
Macrophages (\%) & $91(87-93)$ & $97(77-98)$ & $90(65-99)$ \\
Lymphocytes (\%) & $9(4-13)$ & $3(0-20)$ & $9(1-25)$ \\
Neutrophils (\%) & $0(0-3)$ & $1(0-3)$ & $1(0-10)$ \\
\hline
\end{tabular}

Notes: ${ }^{*} \mathrm{p}<0.05$ vs nonsmokers.

Abbreviation: COPD, chronic obstructive pulmonary disease.

we were not able to find significant differences in KGF levels between these three groups, neither in blood nor in BAL.

To our knowledge this is the first study that evaluates HGF and KGF levels in BAL and serum in patients with COPD. Two previous studies however have investigated the potential role of HGF and KGF in these patients. Plantier and colleagues (2005) found that fibroblasts harvested from patients with pulmonary emphysema produced in vitro less HGF but similar KGF levels than healthy smokers and nonsmokers. This may seem at variance with our results. Two factors can contribute to explain this apparent discrepancy. First, they studied in vitro the response of a specific cell type (the fibroblast) whereas we studied in vivo the end result of a variety of cell types. Second, they studied patients with very severe COPD who required lung volume reduction surgery or lung transplantation, whereas we studied patients with, mostly, moderate disease. In contrast, the second study by Bonay and colleagues (2005) reported a direct relationship

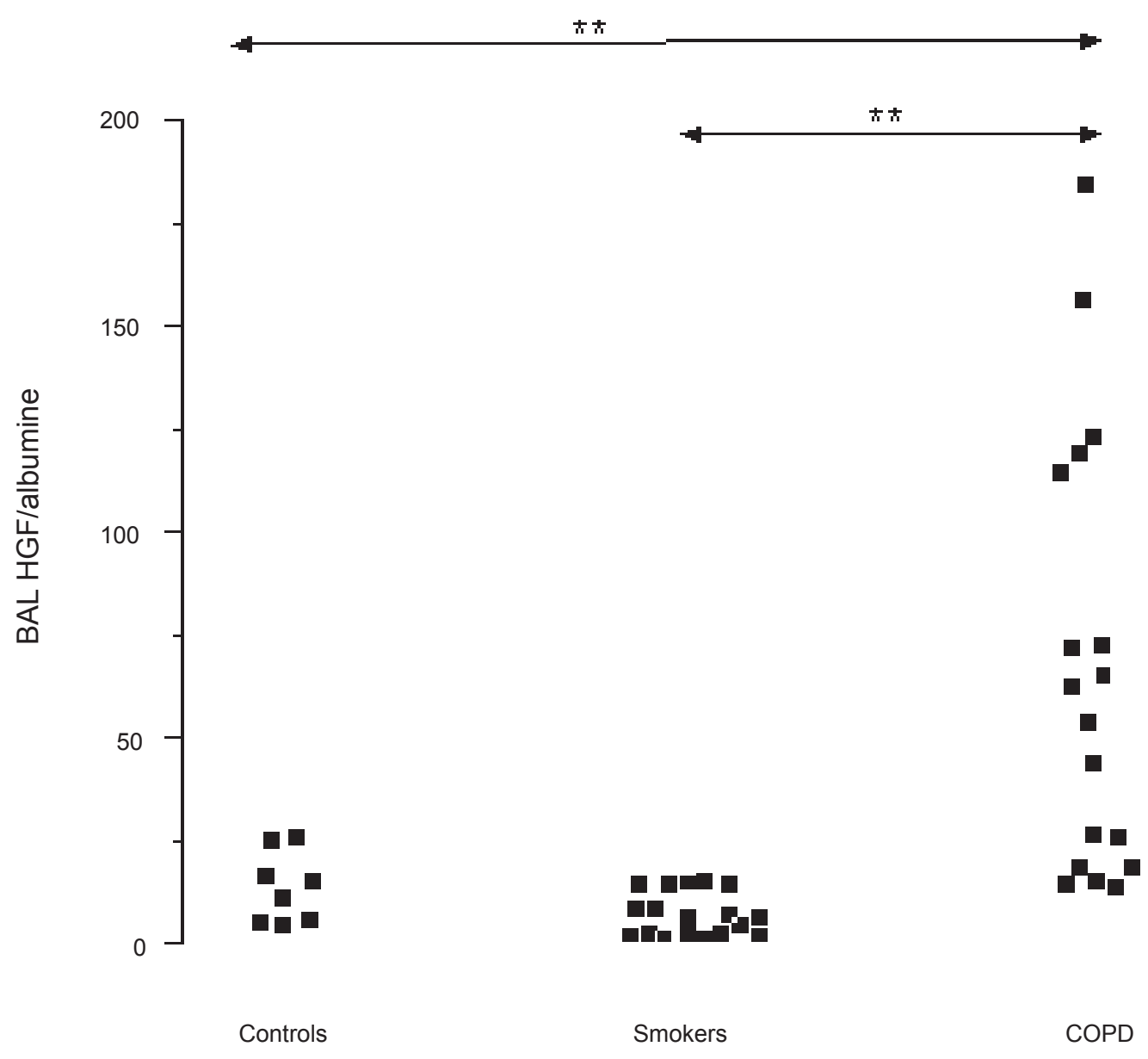

Figure I HGF concentration in BAL in the three groups of individuals studied. Abbreviations: BAL, bronchoalveolar lavage; HGF, hepatocyte growth factor. 


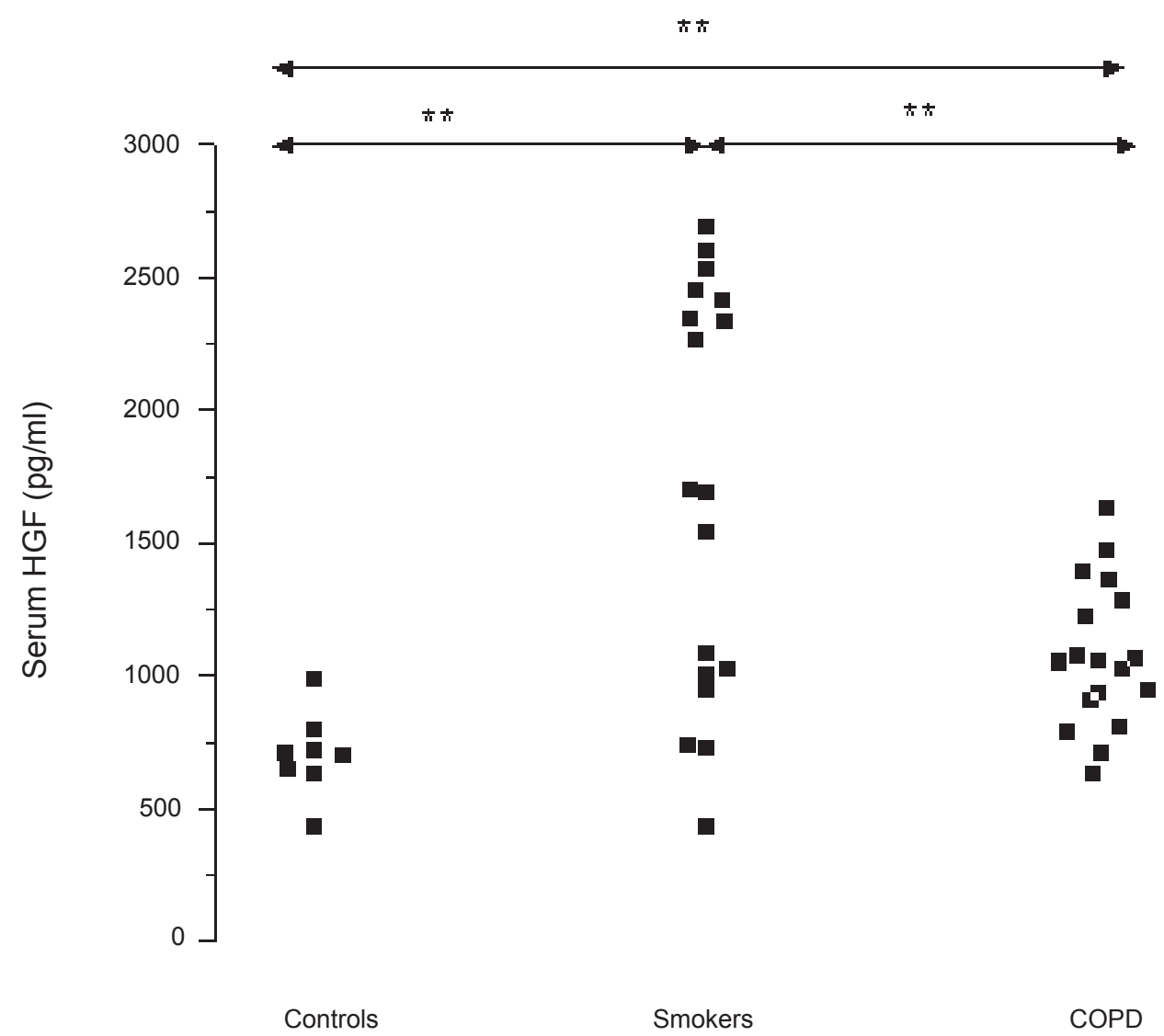

Figure 2 HGF concentration in serum in the three groups of individuals studied. Abbreviation: HGF, hepatocyte growth factor.

between the degree of airflow obstruction and HGF mRNA in lung tissue of smokers with and without COPD, which seem to agree with the results of our study (Figure 1). Interestingly, other growth factors, such as fibroblast growth factor (FGF) -1 and -2 appear also to be increased in bronchial airway wall (Kranenburg et al 2005) and placental growth factor in BAL in patients with COPD (Cheng et al 2008). Therefore, the results of our study in combination with other previous ones (Bonay et al 2005; Kranenburg et al 2005; Cheng et al 2008) seem to indicate that a variety of growth factors are upregulated in the lungs of patients with COPD. In principle, this is consistent with an active repair response. Yet, lung function deteriorates rapidly in COPD, indicating that this response may not fully effective. This is not the case in other conditions characterized by lung injury, such as acute respiratory distress syndrome (Stern et al 2000), pneumonia (Amano et al 2004), and ventilation induced lung injury (Welsh et al 2000), where a similar HGF response has been described. It is possible that differences are related to the chronic and repetitive nature of tissue injury in COPD (mostly tobacco smoking). However, given that the levels of HGF in BAL were not different in active smokers and ex-smokers with COPD, we hypothesize that lung repair may be insufficient or inadequate in COPD.

Previous published studies have shown a relationship between HGF and neutrophil count in BAL fluid in different pulmonary diseases, suggesting that alveolar neutrophils play a major role in HGF production in the lung (Sakai et al 1997; Jaffre et al 2002). In contrast, we did not find such a correlation. This discrepancy could be due to the fact that previous studies evaluated different diseases (with different pathogeny) such as acute respiratory failure (Jaffre et al 2002) and interstitial lung disease (Sakai et al 1997). It is likely that the response to lung injury in COPD may be different (Barnes 2004) and include activated cells, cytokines, and oxidative stress that were not measured in the present study.

Studies in control subjects were unable to detect HGF in BAL fluid or its concentration was very low (Yamanouchi et al 1998; Stern et al 2000). This is also at variance with our results, because our controls were not healthy individuals and patients that required a bronchoscopy for a variety of clinical reasons.

Because COPD has a systemic component (Agusti et al 2003), and both HGF and KGF are also secreted by 
extrapulmonary cells (Mason 2002; Steiling et al 2004), it was also of interest to to analyze their concentration in serum. Previous investigations have reported that serum HGF levels increase after pneumonectomy (Sugahara et al 1998), smoking (Chen et al 2006) and in several acute and chronic disorders such as liver, kidney, and cardiovascular disease (Borawski et al 2002; Ozden et al 2004). More recently, Palange and colleagues (2006) found increased HGF serum concentrations in patients with COPD compared to never smokers. This latter observation fully agrees with our results, albeit we extend their observations to include smokers with normal lung function (Table 1). Like Palange and colleagues (2006) we found that HGF serum levels were higher in COPD patients than in never smokers, but this increase was much enhanced in smokers with normal lung function (Figure 2). This may suggest a blunted systemic response that may potentially limit lung repair. Alternatively, a decreased systemic level of HGF compared to smokers with normal lung function may also reflect increased consumption in the lungs of patients with COPD. In contrast to HGF findings, we do not find significant differences in KGF levels between groups, neither in BAL or blood, because most values were below the detection limit of the technique. We do not think that this is due to technical reasons because we used same methodology used in previous (Plantier et al 2005). Alternatively, given that the three groups of subjects studied showed very low KGF levels, this may indicate that KGF is not involved in the pathogenesis of smoking related diseases, at variance with other disease states like ALI (Verghese et al 1998).

Several methodological aspects of our study deserve comment. First, because it is known that smoking increases HGF (Chen et al 2006), we confirmed that participants refrained from smoking 12 hours before bronchoscopy by measuring the exhaled CO concentration (which was lower than $10 \mathrm{ppm}$ in all participants). Second, albeit patients with COPD had higher smoking exposure that smokers with normal lung function we do not believe that this influenced our results because we did not find any correlation between smoking exposure (pack-yrs) and levels of growth factors. Third, in patients with lung cancer, an overexpression of HGF in lung tissue close to the tumor has been reported (Chen et al 2006). Yet, we think that this did not biased our results because we studied patients with Stage I lung cancer in whom the over expression of HGF is negligible ( Chen et al 2006), BAL was always performed in the lung without chest X-ray anomalies and HGF levels were not different in smokers with and without cancer. Fourth, although steroids can modulate the concentration of growth factors (Blanquaert et al 2000), results were unchanged after excluding the 4 patients treated with ICS. Likewise, although infection can also influence growth factor concentration (Nayeri et al 2002), we excluded this potential confounding effect on the basis of negative cultures of PBS samples.

\section{Conclusion}

Our study reports that the levels of HGF (but not those of $\mathrm{KGF}$ ) in BAL fluid were higher in patients with COPD than in smokers with normal lung function or never smokers. Interestingly, these results were not mirrored in the systemic circulation, where only smokers with normal lung function (but not patients with COPD) were able to mount a vigorous HGF response. Overall, these results address a still poorly understood but potentially very relevant area of repair in COPD, the true therapeutic holy grail in this devastating and progressive disease.

\section{Acknowledgments}

The authors thank the participating individuals for their collaboration in the study and Francesca Bauzà and Angels Noguera for their help during the study. This study was supported in part by SEPAR-2002.

\section{References}

Agusti AG, Noguera A, Sauleda J, et al. 2003. Systemic effects of chronic obstructive pulmonary disease. Eur Respir J, 21:347-60.

Amano H, Morimoto K, Senba M, et al. 2004. Essential contribution of monocyte chemoattractant protein-1/C-C chemokine ligand-2 to resolution and repair processes in acute bacterial pneumonia. J Immunol, 172:398-409.

[ATS] American Thoracic Society. 1995. Standardization of Spirometry, 1994 Update. American Thoracic Society. Am J Respir Crit Care Med, 152:1107-36

Barnes PJ. 2004. Mediators of chronic obstructive pulmonary disease. Pharmacol Rev, 56:515-48.

Blanquaert F, Pereira RC, Canalis E. 2000. Cortisol inhibits hepatocyte growth factor/scatter factor expression and induces c-met transcripts in osteoblasts. Am J Physiol Endocrinol Metab, 278:E509-15.

Boismenu R, Havran WL. 1994. Modulation of epithelial cell growth by intraepithelial gamma delta T cells. Science, 266:1253-5.

Bonay M, Boutten A, Lecon-Malas V, et al. 2005. Hepatocyte and keratinocyte growth factors and their receptors in human lung emphysema. BMC Pulm Med, 5:13.

Borawski J, Mysliwiec M. 2002. Serum hepatocyte growth factor is associated with viral hepatitis, cardiovascular disease, erythropoietin treatment, and type of heparin in haemodialysis patients. Nephrol Dial Transplant, 17:637-44.

Chen JT, Lin TS, Chow KC, et al. 2006. Cigarette smoking induces overexpression of hepatocyte growth factor in type II pneumocytes and lung cancer cells. Am J Respir Cell Mol Biol, 34:264-73.

Cheng SL, Wang HC, Yu CJ, et al. 2008. Increased expression of placenta growth factor in COPD. Thorax, 63:500-6.

Dohi M, Hasegawa T, Yamamoto K, et al. 2000. Hepatocyte growth factor attenuates collagen accumulation in a murine model of pulmonary fibrosis. Am J Respir Crit Care Med, 162:2302-7.

Jaffré S, Dehoux M, Paugam C, et al. 2002. Hepatocyte growth factor is produced by blood and alveolar neutrophils in acute respiratory failure. Am J Physiol Lung Cell Mol Physiol, 282:L310-5. 
Kranenburg AR, Willems-Widyastuti A, Mooi WJ, et al. 2005. Chronic obstructive pulmonary disease is associated with enhanced bronchial expression of FGF-1, FGF-2, and FGFR-1. J Pathol, 206:28-38.

Mason RJ. 2002. Hepatocyte growth factor. The key to alveolar septation? Am J Respir Cell Mol Biol, 26:517-20.

Nayeri F, Brudin L, Darelid J, et al. 2002. Hepatocyte growth factor may act as an early therapeutic predictor in pneumonia. Scand J Infect Dis, 34:500-4.

Ozden M, Kalkan A, Demirdag K, et al. 2004. Hepatocyte growth factor (HGF) in patients with hepatitis B and meningitis. $J$ Infect, 49:229-35.

Palange P, Testa U, Huertas A, et al. 2006. Circulating haemopoietic and endothelial progenitor cells are decreased in COPD. Eur Respir $J$, 27:529-41.

Plantier L, Marchand-Adam S, Marchal-Somme JM, et al. 2005. Defect of hepatocyte growth factor production by fibroblasts in human pulmonary emphysema. Am J Physiol Lung Cell Mol Physiol, 288:L641-7.

Pons J, Sauleda J, Ferrer JM, et al. 2005. Blunted gamma delta T-lymphocyte response in chronic obstructive pulmonary disease. Eur Respir $J$, 25:441-6.

Rabe KF, Hurd S, Anzueto A, et al. 2007. Global strategy for the diagnosis, management, and prevention of chronic obstructive pulmonary disease: GOLD executive summary. Am J Respir Crit Care Med, 176:532-55.

Roca J, Sanchis J, Agustí-Vidal A, et al. 1986. Spirometric reference values for a Mediterranean population. Bull Eur Physiopathol Respir, 22:217-24

Sakai T, Satoh K, Matsushima K, et al. 1997. Hepatocyte growth factor in bronchoalveolar lavage fluids and cells in patients with inflammatory chest diseases of the lower respiratory tract: detection by RIA and in situ hybridization. Am J Respir Cell Mol Biol, 16:388-97.
Sekine K, Fujishima S, Aikawa N. 2004. Plasma hepatocyte growth factor is increased in early-phase sepsis. J Infect Chemother, 10:110-4.

Shigemura N, Sawa Y, Mizuno ST, et al. 2005. Amelioration of pulmonary emphysema by in vivo gene transfection with hepatocyte growth factor in rats. Circulation, 111:1407-14.

Steiling H, Muhlbauer M, Bataille F, et al. 2004. Activated hepatic stellate cells express keratinocyte growth factor in chronic liver disease. $\mathrm{Am} \mathrm{J}$ Pathol, 165:1233-41.

Stern JB, Fierobe L, Paugam C, et al. 2000. Keratinocyte growth factor and hepatocyte growth factor in bronchoalveolar lavage fluid in acute respiratory distress syndrome patients. Crit Care Med, $28: 2326-33$.

Sugahara K, Matsumoto M, Baba T, et al. 1998. Elevation of serum human hepatocyte growth factor (HGF) level in patients with pneumonectomy during a perioperative period. Intensive Care Med, 24:434-7.

UlichTR, Yi ES, LongmuirK, et al. 1994. Keratinocyte growth factor is a growth factor for type II pneumocytes in vivo. J Clin Invest, 93:1298-306

Verghese GM, Cormick-Shannon K, Mason RJ, et al. 1998. Hepatocyte growth factor and keratinocyte growth factor in the pulmonary edema fluid of patients with acute lung injury. Biologic and clinical significance. Am J Respir Crit Care Med, 158:386-94.

Welsh DA, Summer WR, Dobard EP, et al. 2000. Keratinocyte growth factor prevents ventilator-induced lung injury in an ex vivo rat model. Am J Respir Crit Care Med, 162(3 Pt 1):1081-6.

Wimberley NW, Bass JB Jr, Boyd BW, et al. 1982. Use of a bronchoscopic protected catheter brush for the diagnosis of pulmonary infections. Chest, 81:556-62.

Yamanouchi H, Fujita J, Yoshinouchi T, et al. 1998. Measurement of hepatocyte growth factor in serum and bronchoalveolar lavage fluid in patients with pulmonary fibrosis. Respir Med, 92:273-8. 
